\title{
Nurses knowledge, attitudes, practices and familiarity regarding disaster and emergency preparedness - Saudi Arabia
}

\author{
Fatma Abdelalim Abdelghany Ibrahim \\ Faculty of Nursing, Taibah University, Medina, Saudi Arabia, Faculty of Nursing, Department of Community Health Nursing, University \\ of Fayoum, Fayoum, Egypt
}

Email address:

fatmasefaan@gmail.com

To cite this article:

Fatma Abdelalim Abdelghany Ibrahim. Nurses Knowledge, Attitudes, Practices and Familiarity Regarding Disaster and Emergency Preparedness - Saudi Arabia. American Journal of Nursing Science. Vol. 3, No. 2, 2014, pp. 18-25. doi: 10.11648/j.ajns.20140302.12

\begin{abstract}
The number of reported natural and human-made disasters continues to rise worldwide. Nurses comprise the highest percent of health and medical workforce. Nurses must understand the national disaster management cycle. The present study was aimed to examine nurses' knowledge, attitudes, practices and familiarity regarding disaster and emergency preparedness-Saudi Arabia. Cross-sectional descriptive study was conducted using five tools to obtain data from 252 two registered batches of bridging nurses students. Five tools were demonstrated to collect data about demographic data, questionnaire for knowledge, attitude and practice to measure disaster preparedness and emergency preparedness information questionnaire to measure nurses' familiarity. The study findings revealed that the mean age score was $26.36 \pm 1.82$ and for the knowledge level was $21.2 \pm 6.0$. A highly significant difference was found for attitude and practice regarding disaster preparedness as well familiarity concerned emergency preparedness $\mathrm{P} \leq .000$. Based on the present study results; lacking of knowledge and practices with acceptable level of attitude regarding disaster preparedness and neutral familiarity with emergency preparedness were concluded. Thus an integration of clearly titled theory and practice teaching courses about disaster and emergency preparedness into nursing curricula are crucial needed and provided in respect to their learning/training preferences. Further, follow up research are necessary for maximizing nursing education and nursing quality in these critical areas applied to healthcare and community setting.
\end{abstract}

Keywords: KAP, Familiarity, Disaster, Emergency, Preparedness

\section{Introduction}

Disasters occur every day somewhere in the world with dramatic impact on individuals, families and communities. Whether the disaster is a single family house fire or a tsunami that devastates a community, the quality of life is threatened. World Disasters Report 2007 reported a 60\% increase in disasters in the last decade (1997-2006) over the previous decade (1987-1996). Additionally, the number of reported deaths grew from 600000 to over 1.2 million. At the same time, the number of people affected rose from 230 million to 270 million, a $17 \%$ increase [1].

Developing nations are particularly vulnerable due to the lack of funding for disaster preparedness and the impact of disasters on the health care, economic and social infrastructure of the affected region and subsequently, the country. Disasters can change the face of a developing nation in seconds, wiping out years of development. Nations with greater resources are usually able to move more quickly to restore the infrastructure and economy. However, no matter where the disaster happens, the impact on the population and community can be devastating, leaving no nation, region or community immune. The number of reported natural and human-made disasters continues to rise worldwide. [2].

Disaster preparedness, including risk assessment and multidisciplinary management strategies at all system levels, is critical to the delivery of effective responses to the short, medium, and long-term health needs of a disaster-stricken population. Meanwhile, emergency preparedness refers to the preparedness pyramid which identifies planning, infrastructure, knowledge and capabilities, and training as 
the major components of maintaining a high level of preparedness [3-4]. Disasters can be divided into three categories; natural events- such as storms, drought, earthquakes, disease epidemic, technological events-such as explosions, structure collapse, radiological accidents, civil/political events- such as strikes, terrorism, biological warfare [5].

A major concern facing public health nurses, especially in third-world communities, is the increase in vector-borne illnesses as a result of climatic changes. Malaria continues to be prevalent among communities in Africa and claims 1 in 5 children in Sub-Saharan Africa [6]. West Nile virus may occur in drought conditions, and natural predators of mosquitoes are greatly reduced during drought. Dengue and malaria thrive in wet conditions such as flooding and tropical rainy seasons [7-8].

Nursing interventions and management of vector-borne illnesses are also important in the aftermath of disasters when waters become stagnant or gastrointestinal disease becomes prevalent due to unsanitary or over-crowded conditions that result from lack of electricity and/or plumbing. Advanced planning and mitigation are crucial for all countries and at all levels of government. It is especially imperative for healthcare providers to have a thorough knowledge of what lies ahead to take decisive action for training and mock-drills $[1,2,7]$.

The ICN Framework of Disaster Nursing Competencies and recognized an accelerated and present need to build capacities of nurses at all levels in order to "safeguard populations, limit injuries and deaths, and maintain health system functioning and community well-being, in the midst of continued health threats and disasters" [2].

The PAHO and WHO have issued a call for countries to undertake six core actions to make their health facilities safe during emergencies: assess the safety of hospital, protect and train health workers for emergencies, plan for emergency response, design and build resilient hospitals, adopt national policies and programs for safe hospitals, and protect equipment, medicines and supplies. Nurses will be intimately involved with all of these goals [9-10].

Nurses comprise the highest percent of health and medical workforce. Nurses must understand the national disaster management cycle. Without nursing integration at every phase, communities and clients lose a critical part of the prevention network, and the multidisciplinary response team loses a first-rate partner. Eleven million nurses worldwide form the backbone of the health care system and are the frontline health care workers who are in direct contact with the public contribute to health of individuals, families, communities, and the globe [11].

Schools of nursing offer little or no information on disaster nursing and there is shortage of trained instructors/faculty [11]. Although training and education have long been accepted as integral did not base nor standardized, the need for effective evidence based disaster training of healthcare staff at all levels, including the development of standards and guidelines for training in the multi disciplinary health responses in major events, has been designated by the disaster response community as a high priority. The role of nurses during disasters has expanded from simply caring for the sick and injured to development of the ability to react to a disaster in terms of preparedness, mitigation, response, recovery and evaluation Nurses need to have the knowledge and skills to employ an effective approach to respond to critical situations [12]. Thus, the present study was aimed to examine nurses' knowledge, attitudes, practices and familiarity regarding disaster and emergency preparedness-Saudi Arabia.

\section{Materials and Methods}

\subsection{Design}

Cross-sectional descriptive study was utilized to conduct the present study

\subsection{Target Population}

A total of 252 of two (2) registered batches of bridging nurses students were recruited, throughout the academic period between March 2012 / 2014. The study participants' were technical nurses worked in different healthcare settings up to ten years then back to the nursing college to study four to five complementary semesters to obtain bachelor nursing degree.

\subsection{Tools of Data Collection}

Five tools were self administered to collect data about;

1. Demographics information as; age, department, years of experience, place of residence.

2. Knowledge questionnaire on disaster preparedness consisted of 47 objective questions; MCQ and T \& F derived from [13-14], covered questions about disaster management and preparedness. Each question categorized as correct $=1$ and incorrect $=0$

3. Attitudes checklist about disaster planning consisted of eleven item categorized as agree, disagree and unsure adopted from [14] with some modifications done to suit the present study.

4. Practices currently taking place included questions about disaster drills done at their healthcare setting, what type of drills is done, ongoing training, how often, disaster plan update and how often developed by [14].

5-Emergency Preparedness Information Questionnaire (EPIQ) was used. It developed by Wisniewski et al in 2004 [15] and has been employed in many studies to measure familiarity of emergency preparedness. There is Wisconsin Nurses Association (WNA's) permission to use the EPIQ tool. The questionnaire was composed of two sections. Section one concerned with the overall familiarity with emergency preparedness included (45) familiarity responses and (11) subsets. The subsets were included; familiarity with emergency preparedness terms \& activities composed of (7 questions), the incident command system (ICS) (8 questions), ethical issues in triage (4 questions), 
epidemiology and surveillance (4 questions), isolation/quarantine (2 questions), decontamination (3 questions), communication/connectivity (7 questions), psychological issues (4 questions), special populations (2 questions), accessing critical resources (3 questions), overall familiarity. This questionnaire was categorized through likert scale as "not at all familiar", "slightly familiar", "somewhat familiar", "Moderately familiar", "Extremely familiar and scale was ranged from extremely familiar $=1$ to not at all familiar $=5$. Section two is about learning/training preferences of training format, course length, and nurses access to electronic training/educational information.

\subsection{Ethical Consideration}

Purpose and nature of the present study was explained to the study participants and that participation was appreciated. Also, the target population was announced that participation of the study may not have received prior training and/or previous exposure to many of these activities and the goal of this study was to assess information gaps and training needs, and identify any and all areas that need to be addressed. In addition to that is not a test and no way reflects on personally so didn't worry if they were lacking of information or unfamiliar with certain areas. Every single study unit was informed that participating in the research was voluntary. Oral consent was obtained from participants. Confidentiality of the information was observed by anonymity not mentioning name of the study units in the questionnaire and not being distributed by the researcher. The questionnaires completed were coded and no names were put on the questionnaires. Name links to the codes were kept in a coded drawer. Information was kept confidential and only pooled data was to be presented.

\subsection{Procedure}

Official permission was taken from the nursing faculty dean to conduct the present study. Two weeks before time of data collection; an announcement posters was placed on the advertisement board included orientation details such as; purpose, nature, ethical consideration and procedure of the present study. After the study participants' had finished their first academic work semester (2013/2014), a number was assigned to each student that used via demonstration of data collection tools, The data collection tools were carried out in two sessions separated by 30 minutes break at the college lectures rooms. In session one the demographic data, knowledge, attitude and practice were distributed and demonstrated. At the second session the students were given EPIQ. Each session was taken average of 20:30 minutes to fill in.

\subsection{Statistical Design}

The data were statistically analyzed by descriptive criteria such as number, percentage, mean and standard deviation; also inferential statistics t-test using SPSS 21 and $P$ value was set at 0.5 .

\section{Results}

\section{Section 1: Demographic Characteristics}

Almost two third (67.1\%) of the study participants were aged between $>25: 30$ year old with mean score of $26.36 \pm 1.82$ The period of experience for three quarter of them $(76.2 \%)$ ranged between $<3: 6$ years. Nearly half of them $(49.2 \%)$ were working in the critical care units and medical surgical departments (25.8 and $23.4 \%$ respectively) (table 1 )

Table 1. Demographic characteristics of study participants $(n=252)$.

\begin{tabular}{lll}
\hline Variable & No $(\%)$ & Mean \pm S D \\
\hline Age by year & \\
$\leq 20$ & $1(0.4)$ & $26.36 \pm 1.82$ \\
-25 & $82(32.5)$ & \\
-30 & $169(67.1)$ \\
Period of experience in year & \\
$<3$ & $108(42.9)$ \\
-6 & $84(33.3)$ \\
-9 & $60(23.8)$ \\
Department of work & \\
Not working & $2(0.8)$ \\
Critical units & $65(25.8)$ \\
Pediatrics & $22(8.7)$ \\
Medical surgical & $59(23.4)$ \\
Theater room & $27(10.7)$ \\
Kidney Dialysis & $10(4.0)$ \\
Outpatient clinic & $22(8.7)$ \\
MCH, Maternity hospital & $29(11.5)$ \\
Administrative departments, & $10(4.0)$ \\
\hline & $6(2.4)$ \\
\hline
\end{tabular}

\section{Section 2: Knowledge}

Table 2 shows that the knowledge level regarding disaster preparedness among two third of the study sample fallen of the category between 13-25 degree out of 47 degree with mean score of $21.2 \pm 6.0$ with highly significant differences $(t=55.82 \& \mathrm{P} \leq .000)$.

Table 2. Knowledge level category regarding disaster among study participants $(n=252)$

\begin{tabular}{ll}
\hline Knowledge level categories & No $(\%)$ \\
\hline scores out of 47 degree & \\
$1-12$ & $14(5.6)$ \\
$13-24$ & $172(68.3)$ \\
$25-36$ & $59(23.4)$ \\
$37-48$ & $7(2.8)$ \\
Mean \pm SD $\quad 21.2 \pm 6.0$ & \\
$\mathrm{t}(55.82) \quad \& \mathrm{P} \leq(.000)(\mathrm{HS})^{*}$ & \\
\hline
\end{tabular}

(HS)* Highly significant 


\section{Section 3: Attitudes}

Table 3 illustrates the percentages of agreement regarding disaster preparedness attitudes of the study participants which were as following; (69.8) agreed to the need to knowledge about disaster plans, (73) to management should be adequately prepared should a disaster occur, (57.9) to disaster planning is for all people in the healthcare setting, (77.8) to potential hazards likely to cause disaster should be identified and dealt with, (83.7) to training is necessary for all healthcare management, (82.2) to having disaster plan is necessary, (73.4) to disaster plans need to be regularly updated, (47.6) to disasters are likely to happen in any healthcare setting, (60.3) to disaster management is for all healthcare team, (73.4) to disaster simulations should occur frequently in the hospital, and (79.8) to drills should be conducted in the hospital with highly significant difference $(\mathrm{t}=78.979$ and $\mathrm{P} \leq .000)$.

Table 3. Attitude regarding disaster preparedness among the study participants $(n=252)$

\begin{tabular}{|c|c|c|c|}
\hline Attitude variables & Agree & Disagree & Unsure \\
\hline \multicolumn{4}{|l|}{ No $(\%)$} \\
\hline 1. I need to knowledge about disaster plans & $176(69.8)$ & $64(25.4)$ & $12(4.8)$ \\
\hline 2. Management should be adequately prepared should a disaster occur. & $184(73.0)$ & 57 (22.6) & $11(4.4)$ \\
\hline 3. Disaster planning is for all people in the healthcare setting. & $146(57.9)$ & $91(36.1)$ & $15(6.0)$ \\
\hline 4. Potential hazards likely to cause disaster should be identified and dealt with. & $196(77.8)$ & $29(11.5)$ & $27(10.7)$ \\
\hline 5. Training is necessary for all healthcare team. & $211(83.7)$ & $29(11.5)$ & $12(4.8)$ \\
\hline 6. It is necessary to have a disaster plan. & $207(82.2)$ & $29(11.5)$ & $16(6.3)$ \\
\hline 7. Disaster plans need to be regularly updated & $185(73.4)$ & $43(17.1)$ & $24(9.5)$ \\
\hline 8. Disasters are likely to happen in any healthcare setting & $120(47.6)$ & $97(38.5)$ & $35(13.9)$ \\
\hline 9. Disaster management is not limited to nurses and doctors & $152(60.3)$ & $80(31.7)$ & $20(8)$ \\
\hline 10. Disaster simulations should occur frequently in the healthcare setting & $185(73.4)$ & $46(18.3)$ & $21(8.3)$ \\
\hline 11. Drills should be conducted in the hospital & 201(79.8) & $29(11.5)$ & $22(8.7)$ \\
\hline t $\quad 78.979$ & & & \\
\hline
\end{tabular}

\section{Section 4: Practices}

Table 4 indicates that $(48.8 \%)$ of the study participants' were knew that disaster drills are done at their healthcare setting. 33.7\% said they are not done and $17.5 \%$ didn't know. $23.4 \%$ didn't know the type of drills done. Of the remaining $41.7 \%$ they mentioned code blue and fire evacuation. $38.9 \%$ believed there is ongoing training at their healthcare setting. 31.7 stated that training was done yearly, $34.5 \%$ not done and $33.8 \%$ didn't know. $31 \%$ said disaster plans are regularly updated. $29.8 \%$ said they are not regularly updated and $39.2 \%$ didn't know. $45 \%$ believed it is done yearly and $55 \%$ didn't know. 3\% said it was done every 6 months. $1 \%$ said it is done every 3-6 months and 10\% said when the need arises. A highly significant difference of practices level was found as $\mathrm{t} 46.41$ and $\mathrm{P} \leq .000$.

Table 4. Percentages of the study participants' practice regarding disaster preparedness $(n=252)$

\begin{tabular}{|c|c|c|c|c|}
\hline \multirow{2}{*}{\multicolumn{2}{|c|}{ Variable }} & yes & no & don't know \\
\hline & & No $(\%)$ & & \\
\hline \multicolumn{2}{|c|}{ Are disaster drills done at your hospital? } & $123(48.8)$ & $85(33.7)$ & $44(17.5)$ \\
\hline \multicolumn{2}{|c|}{ If yes, what type of drills is done? } & $105(41.7)^{*}$ & $88(34.9)$ & $59(23.4)$ \\
\hline \multicolumn{2}{|c|}{ Is there ongoing training? } & $98(38.9)$ & $87(34.5)$ & $67(26.6)$ \\
\hline \multicolumn{2}{|l|}{ If yes, how often? } & $80(31.7)^{* *}$ & $87(34.5)$ & $85(33.8)$ \\
\hline \multicolumn{2}{|c|}{ Is the disaster plan periodically updated? } & $78(31)$ & $75(29.8)$ & $99(39.2)$ \\
\hline \multirow[t]{4}{*}{$\begin{array}{l}\text { If yes, how often? } \\
\text { Category: }\end{array}$} & $\begin{array}{l}\text { Total } \\
\text { Every year }\end{array}$ & $\begin{array}{l}113(45) \\
77(31)\end{array}$ & \multirow[t]{4}{*}{-} & \multirow[t]{4}{*}{$139(55)$} \\
\hline & Every 6 months & $8(3)$ & & \\
\hline & Every 3-6 months. & $4(1)$ & & \\
\hline & When the need arises & $24(10)$ & & \\
\hline $\mathrm{t} \quad 46.41$ & Sig. $\mathrm{P} \leq .000(\mathrm{HS})^{* * *}$ & & & \\
\hline
\end{tabular}

*Code blue and fire evacuation $\quad *$ yearly $\quad \mathrm{HS}^{* * *}$ highly significant 


\section{Section 5: Familiarity with Emergency Preparedness}

Part I: Familiarity with emergency preparedness

Table 5 describes the nurses familiarity responses rate of emergency preparedness $(n=252)$.The results reveals that the majority of responses sum were ranged from very familiar, somewhat familiar and familiar neutral respectively as follows; emergency preparedness terms \& activities were $(37.2,38.5$ and $18.3 \%$ ), for the incident command system and role within it (27.8, 43.7 and $17.8 \%)$, for ethical issues in triage, $(42.5,28.2$ and $16.7 \%)$, for epidemiology and surveillance $(33.0,35.3$ and $21.4 \%$ ), for isolation/quarantine (43.7, 24.2 and $18.7 \%$ ), for decontamination (43.7, 32.1 and $13.1 \%), \quad$ for communication/connectivity (31.3 39.0 and $20.6 \%$ ), for psychological issues $(36.5,33.0$ and $19.8 \%$ ), for special populations (27.7, 41.3 and $18.3 \%$ ), for the accessing critical resources responses ranges $(24.6,36.5$ and $25.4 \%$ ), and for overall familiarity $(25.4,23.8$ and $27.0 \%)$. As well as, the total EPIQ responses was ranged from somewhat familiar, familiar neutral and somewhat not familiar (33.7, 46.8 and $13.1 \%)$ respectively. The overall total of EPIQ was ranged as (1.2, $33.7,46.8,13.1 \& 5.2 \%$ ) for very familiar, somewhat familiar, familiar neutral, somewhat not familiar and not familiar respectively. The mean score was $(2.87 \pm 0.84)$, with highly significant difference was found as ( $\mathrm{t} 54.168 \& \mathrm{P} \leq 0.000)$

Table 5. Description of nurses familiarity responses rate of emergency preparedness $(n=252)$

\begin{tabular}{llllll}
\hline Responses rate to familiarity elements & $\begin{array}{l}\text { Very } \\
\text { familiar (1) }\end{array}$ & $\begin{array}{l}\text { Somewhat } \\
\text { familiar (2) }\end{array}$ & $\begin{array}{l}\text { Familiar } \\
\text { neutral (3) }\end{array}$ & $\begin{array}{l}\text { Somewhat not } \\
\text { familiar (4) }\end{array}$ & $\begin{array}{l}\text { Not familiar } \\
(\mathbf{5})\end{array}$ \\
\hline I- Emergency Preparedness Terms \& Activities & $94(37.2)$ & $97(38.5)$ & $46(18.3)$ & $10(4.0)$ & $5(2.0)$ \\
2. Incident Command System (ICS) and your role within it. & $70(27.8)$ & $110(43.7)$ & $45(17.8)$ & $22(8.7)$ & $5(2.0)$ \\
3. Ethical Issues in Triage. & $107(42.5)$ & $71(28.2)$ & $42(16.7)$ & $24(9.5)$ & $8(3.2)$ \\
4. Epidemiology and Surveillance. & $83(33.0)$ & $89(35.3)$ & $54(21.4)$ & $18(7.1)$ & $8(3.2)$ \\
5. Isolation/Quarantine. & $110(43.7)$ & $61(24.2)$ & $47(18.7)$ & $17(6.7)$ & $17(6.7)$ \\
6. Decontamination. & $110(43.7)$ & $81(32.1)$ & $33(13.1)$ & $16(6.3)$ & $12(4.8)$ \\
7. Communication/Connectivity. & $79(31.3)$ & $98(39.0)$ & $52(20.6)$ & $18(7.1)$ & $5(2.0)$ \\
8. Psychological Issues. & $92(36.5)$ & $83(33.0)$ & $50(19.8)$ & $18(7.1)$ & $9(3.6)$ \\
9. Special Populations. & $70(27.7)$ & $104(41.3)$ & $46(18.3)$ & $21(8.3)$ & $11(4.4)$ \\
10. Accessing Critical Resources. & $62(24.6)$ & $92(36.5)$ & $64(25.4)$ & $23(9.1)$ & $11(4.4)$ \\
11. Overall Familiarity. & $64(25.4)$ & $60(23.8)$ & $68(27.0)$ & $23(9.1)$ & $37(14.7)$ \\
Total EPIQ & $3(1.2)$ & $85(33.7)$ & $118(46.8)$ & $33(13.1)$ & $13(5.2)$ \\
\hline
\end{tabular}

Mean \pm SD $\quad(2.87 \pm 0.84)$

t $54.168 \quad \mathrm{P} \leq .000$ (HS)

Part-II: Participants learning/training preferences.

Figure 1. Shows the percentages of nurses' preferences regarding; learning/training format. The pie chart illustrates that more than half of study sample $(55.2 \%)$ preferences was face to face training while only $2.7 \%$ were preferred online web based learning/training.

Figure 2. Shows percentages agreement on amount of time spend preferences in training. The study findings revealed amount of time spend preferences in training in descending order as; participate in a 2-hour lecture or web-based training, attend an evening workshop, attend a one-day weekend workshop, attend a 2-3 day workshop/conference and take a course for an academic quarter/semester, respectively $(75,67.5,63.5,60.7$ and $59.1 \%)$.

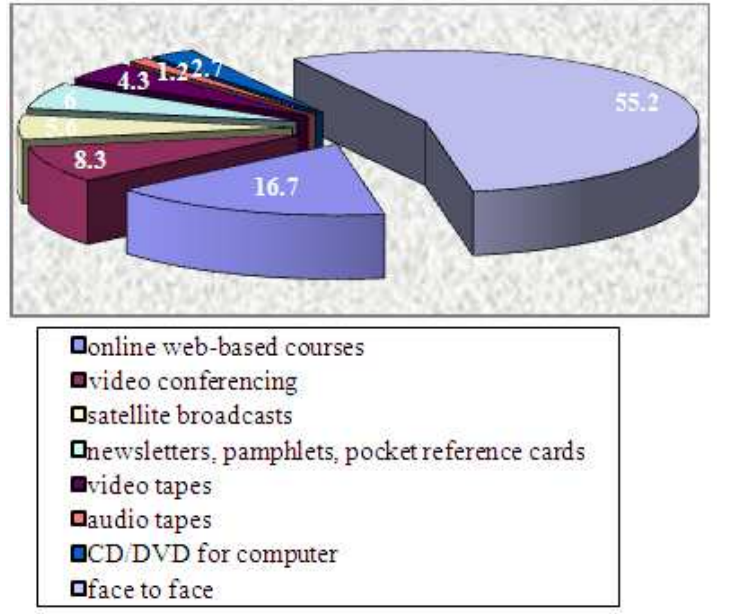

Figure 1. Percentages of nurses learning/training format preferences 


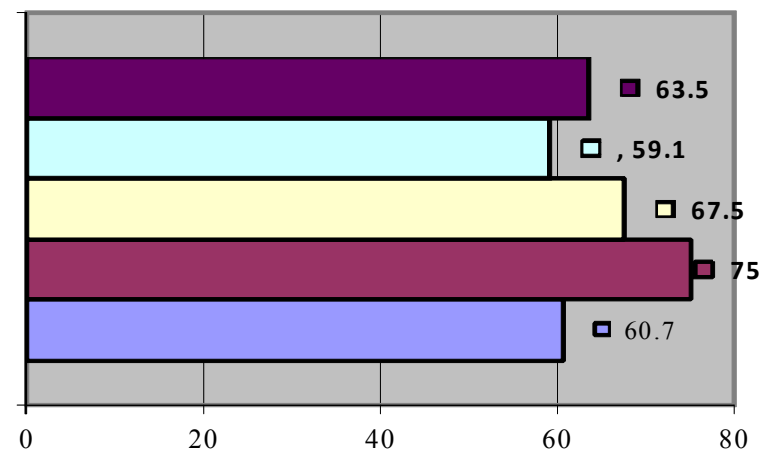

DAttend a one-day weekend workshop

$\square$ Attend an evening workshop

$\square$ Participate in a 2-hour lecture or web-based training

口Attend a 2-3 day workshop/conference

口Take a course for an academic quarter/semester

Figure 2. Percentages agreement on amount of time spend preferences in training

Figure 3 illustrates the nurses' percentages access to electronic training/educational information. The study findings percentages' were as follows; access to a computer at work (73\%), at home (89.7), access to the internet at work (56.3), at home (86.5), access to satellite downlinks at work (38.1), participate in satellite downlinks for training/educational purposes (44.4), used the internet to access information on bioterrorism and/or emergency preparedness (58.3) and allow work hours to be used for learning/educational opportunities related to the job (56.8).

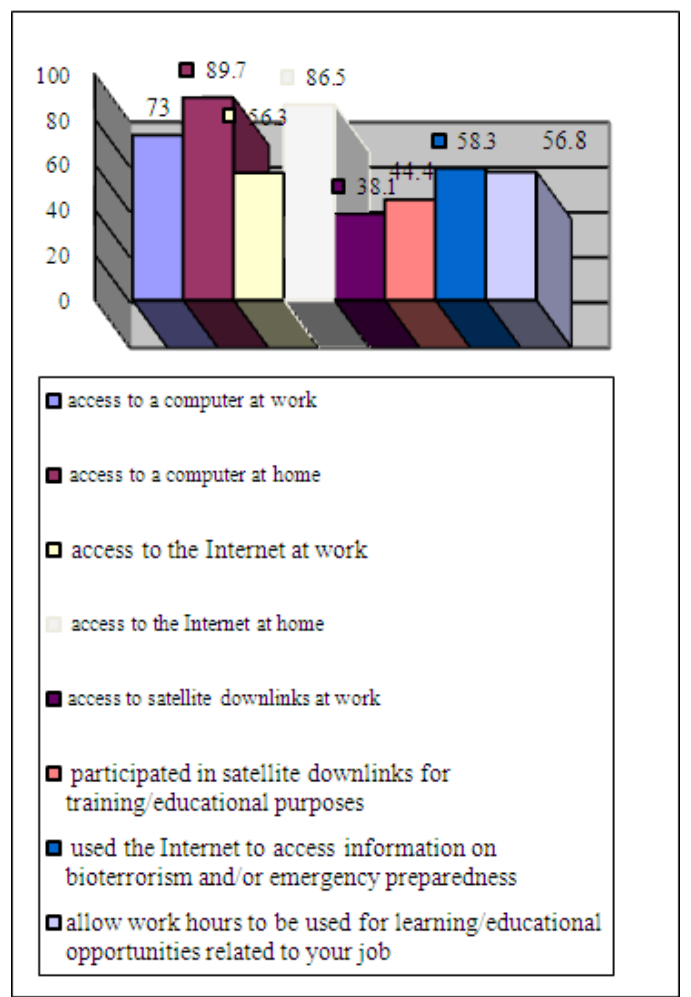

Figure 3. Percentages of nurses access to electronic training/ educational Information

\section{Discussion}

Increasingly frequent global disasters are posing threats to human health and life. The World Health Organization has called for countries to have detailed plans at all levels in order to be prepared for disasters that may arise. Nurses and midwives are frontline workers under stable conditions, but more so during situations of emergencies and crises, working both in pre-hospital as well as in hospital settings. In order to contribute to saving lives and promoting health under such difficult conditions, they need to have the right competencies [2].

The present study was aimed to investigate nurses' knowledge, attitude, practice and familiarity regarding disaster and emergency preparedness-Saudi Arabia. In overall view of the present study findings; the age mean score of the study participants' was 26 year old, the period of experience for three quarter of them ranged between $<3: 6$ years. More than one quarter of them were working in the critical care units (table 1). Regards Knowledge part, the study participants showed lack of their knowledge level in disaster preparedness (mean score was 21.2 ) with highly significant differences $\mathrm{P} \leq .000$ (Table 2 ). While the attitudes of them regarding disaster prepared was accepted except to attitude agreement that disasters are likely to happen in any healthcare setting with highly significant difference $\mathrm{P} \leq .000$ (Table 3). Concerning practices part; the study findings revealed that practices of disaster preparedness was below average level with highly significant differences $\mathrm{P} \leq .000$. On the part of familiarity with emergency preparedness; the overall familiarity was recorded nearest (2.87) to the neutral familiarity with highly significant difference $\mathrm{P} \leq 0.000$ was found (table 5). In the part II concerned with preferences of learning/training. More than half of study sample (55.2\%) preferences was face to face (figure 1). while the amount of time spend preferences in training almost was close to all options (figure 2). In relation to the electronic access training/educational information may be seen as in need for more support especially in internet downloads at work and educational needs related to work (Figure 3)

In respect to knowledge, attitude and practice (KAP) of nurses' preparedness in emergency situations that reflect the features and characteristics of critical situations. A comprehensive knowledge, skills, proficiencies, and the necessary measures in respond to cases such as natural disasters, man-provoked events, chemical, nuclear, biological and explosive cases were included [14]. Nevertheless, there is no specified degree in crisis nursing and there are just short term educational courses [15].

Many KAP studies conducted of nurses' disaster and emergency preparedness. A study undertaken by nurses in Hong Kong concluded that nurses are not adequately prepared for disasters, but are aware of the need for such preparation. Also, that disaster management training should be included in the basic education of nurses [16]. Disaster drills are a valuable means of training healthcare providers to respond to mass casualty incidents from acts of terrorism or public health 
crises [17]. Meanwhile, a cross-sectional descriptive study was conducted using a self-developed questionnaire to obtain data from 607 nurses working in four tertiary hospitals and two secondary hospitals in Fujian, China, in November 2011. Their findings showed that the nurses' average percentage scores on their responses to questions in the domains of knowledge, attitudes and practice were $66.33 \%, 68.87 \%$ and $67.60 \%$, respectively. The results indicate that strategies need to be developed for nurses to improve their knowledge, attitudes and practice [18].

Another study was done to determine KAP of emergency nurse and community health nurse towards disaster management. Researchers found that adequacy of knowledge and practice, and portraying positive attitude was driven by being involved in disaster response and attending disaster-related education. They recommended paramount for health administrators to conduct disaster-related education/ training for front-liners such as emergency and community health nurses to improve their knowledge and practice towards disaster management [19].

Knowledge, skills, and preparedness for disaster management were examined to Jordanian RNs' perceptions. The research findings indicated that Knowledge, skills, and disaster preparedness need continual reinforcement to improve self efficacy for disaster management and there was a need for a consistent national nursing curriculum for disaster preparedness and nationwide drills to increase disaster knowledge, skills, preparedness, and confidence [20]

A comparative study of 4 years undergraduates nursing students' was done to assess the educational needs concerning; disaster preparedness and response in Istanbul and Miyazaki. The study reported that most student nurses had no expectations on skills that could be gained from a disaster preparedness and response course/culture of disaster lecture. Nursing students in both cities seem more likely to participate in disaster preparedness and response courses/lectures. Researchers addressed the need to incorporate mass casualty care and disaster management skills into undergraduate curricula. Core contents for nursing curricula in both cities need to be continued. Outcome competencies must be identified and validated through further research [21]

Most nurses receive little, if any, disaster preparedness education in nursing school. A 2003 survey of 2013 schools of nursing (348 responding) revealed that only 53\% offered content in disaster preparedness, and a mean of 4 hours was devoted to this content. In general, nursing school faculties were inadequately prepared to teach disaster preparedness content [22].

Concerning the nurses' familiarity with emergency preparedness, the need for emergency preparedness training is well documented in the literature. A crucial first step toward designing well written, comprehensive, emergency preparedness curricula is to assess training needs. Additional studies using the revised EPIQ should provide data to assist nurse educators in the development of competency-based, relevant, emergency preparedness curricula [23-27].
In a publication of the Joint Commission on Accreditation of Health Organizations entitled emergency management in healthcare, an all-hazards approach, the JCAHO mandates that hospitals have an all-hazards emergency operations plan. Many national plans are based on the Hospital Incident Command System [28-29].

As well a study utilized the EPIQ to assess of emergency department staff knowledge of emergency preparedness. The results of the survey were found to be similar to the results of the first Wisconsin survey. Results showed that staff scored better in more general areas such as triage and basic first aid. Scores were lower when asked specific questions, such as antidotes to biological agents. The study showed that there is a need for more educational programs in the area of emergency preparedness. The results of the study may be utilized to develop educational programs to further the knowledge of the staff and have them better prepared in disastrous events [13].

Identifying an effective means of teaching hospital disaster preparedness to hospital-based employees is an important task. However, the optimal strategy for implementing such education still is under debate. Efforts were also undertaken to determine the types of educational offerings and class-scheduling options most preferred by nurses [30].

\section{Conclusion and Recommendation}

Based on the present study results; it can be concluded that the level of knowledge and practice were below average with acceptable level of attitude regarding disaster preparedness and neutral familiarity with emergency preparedness were found. Thus an integration of clearly titled theory and practice teaching courses about disaster and emergency preparedness into nursing curricula are crucial needed and provided in respect to their learning/training preferences. Further, follow up research are necessary for maximizing nursing education and nursing quality in these critical areas applied to healthcare and community setting.

\section{Acknowledgments}

Special thanks for the bridging nurses' students for their cooperation and time provided during data collection process.

\section{References}

[1] Y. Klyman, N. Kouppari, \& M. Mukhier, (2007). World disasters report 2007: Focus on discrimination. Geneva: International Federation of Red Cross and Red Crescent Societies.

[2] H. Minami S. Young-Soo (2009). ICN Framework of Disaster Nursing Competencies.C 2009 World Health Organization and International Council of Nurses. ISBN 978-92-95065-79-6 
[3] Texas Board of Nursing (2011). Statistical information. http://www.bne.state.tx.us/about/statistical.

[4] Centers for Disease Control and Prevention: Public health information network, 2010. Available at http:/www.cdc.gov/phin/resources/phinfacts.html. 2010, retrieved from American Red Cross, 2009.

[5] S B Hassmiller, and S A. R Stanley. Public health nursing and the disaster management cycle. Part 4: Issues and approaches in population-centered nursing. $\mathrm{Ch}$ (23) 10023-STANHOPE-9780323080019

[6] K. Shishani, Disaster Nursing golden lecture. Community Health Nursing. Kawkab.shishani@gmail.com.

[7] Report of Centre for Research on the Epidemiology of Disasters Aug 2013 - Executive Summary. 13

[8] A. Laura. Stokowski Ready, Willing, and Able: Preparing nurses to respond to disasters. 2012

[9] R. Garfield, N. Padilla. R. La-Porte. WHO Collaborating Center University of Pittsburgh. June 8, 2009. http://www.pitt.edu/ super1/lecture/lec35051/index.htm

[10] D.B Reissman, and J Howard. Responder safety and health: preparing for future disasters. Mt Sinai J Med. 2008 Mar-Apr; 75(2):135-41 (Dorsey, 2009, p. iv).

[11] E. Hsu, and L. Tamara. Health care worker competencies for disaster training, BMC Medical Education, 2006,6:19 Available from:

http://www.biomedcentral.com/1472-6920/6/19

[12] E. Weiner. Preparing nurses internationally for emergency planning and response. Online Journal of Issues in Nurs.2006;11(3).

[13] P. Miller (2011). An Assessment of emergency department staff knowledge of emergency preparedness. Published thesis Tina Volz, Committee Chair Ruth Hen thorn Committee Member. UMI Copyright 2011 by Pro Quest LLC.

[14] R. M. Moabi (2008). Knowledge, attitudes and practices of health care workers regarding disaster Preparedness At Johannesburg Hospital in Gauteng Province, South Africapublished master thesis of public health. Student No: 9212062N. Inc.doi: 10.1111/j.1525-1446.2009.00825.x

[15] Emergency preparedness information questionnaire (EPIQ). Survey Monkey 2009site:http//www.surveymonkey.com.

Web

[16] O.W. Fung, A.Y. Loke, and C.K. Lai. Disaster preparedness among Hong Kong nurses. 1:J Adv Nurs. 2008 Jun; 62(6):698-703.

[17] K. Gebbie, , K. Qureshi, (2006). A historical challenge: nurses and emergencies. The Online Journal of Issues in Nursing.

[18] L Jiang, H-G He, W-G Zhou, S-H Shi, T-T Yin, Kong. Knowledge, attitudes and competence in nursing practice of typhoon disaster relief work among Chinese nurses: A questionnaire survey. International Journal of Nursing Practice. 2013; DOI:10.1111/ijn.12214.
[19] N Ahayalimudin, A Ismail and I M Saiboon. Disaster management: a study on knowledge, attitude and practice of emergency nurse and community health nurse BMC Public Health 2012, 12(Suppl

2):A3 doi:10.1186/1471-2458-12-S2-A3

http://www.biomedcentral.com/1471-2458/12/S2/A3

[20] M A Al Khalaileh, E Bond, J A Alasad Jordanian nurses'. perceptions of their preparedness for disaster management. International emergency nursing 2012; 20(1):14-23. DOI:10.1016/j.ienj.2011.01.001

[21] S D Oztekın, E E Larson, G A Uğraş, S Yüksel. Educational needs concerning disaster preparedness and response: A comparison of undergraduate nursing students from Istanbul, Turkey, and Miyazaki, Japan. Japan Journal of Nursing Science.2014; 11(2):94-101. DOI:10.1111/jjns. 12008

[22] C. A. Bishop. Faculty Assessments of the Potential for Emergency Events on their Campus and their Perceived Preparedness to Respond (2013). Ed.D. Dissertations. Paper 51

[23] Garbutt S J, and Peltier J and Joyce J Fitzpatrick. Evaluation of an instrument to measure nurses' familiarity with rmergency preparedness. Military Medicine Oct 31, 2008 20:00 EDT

[24] H. E. Jacobson, and F.S. Mas, J. P. Turley, J. Miller, and M. Kim. Self-Assessed Emergency Readiness and Training Needs of Nurses in Rural Texas. Public Health Nursing Vol. 27 No. 1-2010 Wiley Periodicals,

[25] S T Baack (2011). Analysis of Texas Nurses' Preparedness and Perceived Competence in Managing Disasters. Published dissertation. (C) Copyright by Sylvia Baack, 2011

[26] E. Whetzel, G. Walker-Cillo, G.K.Chan, J Trivett. Emergency Nurse Perceptions of Individual and Facility Emergency Preparedness. doi:10.1016/.2011.08.005 Journal of Emergency Nursing Volume 39, Issue 1, Pages 46-52, January 2013 Elsevier Inc.

[27] S.J Garbutt, J.W. Peltier, \& J.J Fitzpatrick (2008). Evaluation of an instrument to measure nurses' familiarity with emergency preparedness. Military Medicine. 1073-1077.

[28] American Association of Colleges of Nursing (AACN). (2011). Nursing shortage fact sheet "Average age of the registered nurse is climbing." Retrieved from http://www.aacn.nche.edu/media-relations/NrsgShortageFS. pdf

[29] B Collander, B Green, Y Millo, C Shamloo, J Donnellan, C DeAtley . Development of an "all-hazards" hospital disaster preparedness training course utilizing multi-modality teaching. Pre-hosp Disaster Med. 2008 Jan-Feb;23(1):63-7; discussion 68-9.

[30] H Hasankhani, F Abdollahzadeh, S V Shams, J Dehghannejad, A Dadashzadeh. Educational needs of emergency nurses according to the emergency condition preparedness criteria in hospitals of Tabriz University of Medical Sciences. Iran J Crit Care Nurs 2012;5(3):159-165 